\title{
Gentrificación en áreas patrimoniales latinoamericanas: cuestionamiento ético desde el caso de Cuenca, Ecuador
}

Gentrificação em áreas patrimoniais latino-americanas: questionamento ético a partir do caso de Cuenca, Equador

Gentrification in Latin American heritage areas: ethical questioning based on the case of Cuenca, Ecuador

Natasha Cabrera-Jara[a,b] (1)

[a] Pontificia Universidad Católica de Chile, Santiago, Chile

[b] Universidad del Azuay, Cuenca, Ecuador

Cómo citar: Cabrera-Jara, N. (2019). Gentrificación en áreas patrimoniales latinoamericanas: cuestionamiento ético desde el caso de Cuenca, Ecuador. urbe. Revista Brasileira de Gestão Urbana, 11, e20180201. https://doi.org/10.1590/21753369.011.e20180201

\section{Resumen}

En las últimas décadas las áreas urbanas patrimoniales en América Latina han experimentado intervenciones públicas y privadas con el fin de conservar su patrimonio y acrecentar su atractivo turístico. Estas actuaciones han desencadenado procesos de gentrificación y desposesión cuyo análisis ético se aborda en este artículo, mediante la construcción de un marco ético de referencia aplicado a un caso específico: Cuenca, en Ecuador. Se inicia con la revisión teórica de la gentrificación y los debates sobre su estudio en América Latina -específicamente en áreas patrimoniales donde se resalta el papel del turismo-, se describe el caso cuencano y se cierra con su análisis ético.

Palabras clave: Gentrificación. Áreas patrimoniales. América Latina. Análisis ético.

\section{Resumo}

Nas últimas décadas, as áreas de patrimônio urbano da América Latina têm sido objeto de intervenções públicas e privadas para conservar seu patrimônio e aumentar sua atração turística. Essas ações desencadearam processos de gentrificação e desapropriação, cuja análise ética é abordada neste artigo por meio da construção de um quadro ético de referência aplicado a um caso específico: Cuenca, no Equador. Inicia-se com a revisão teórica da gentrificação e os debates sobre seu estudo na América Latina - especificamente em áreas patrimoniais em que o papel do turismo é destacado -, o caso de Cuenca é descrito e conclui-se com sua análise ética.

Palavras-chave: Gentrificação. Áreas patrimoniais. América Latina. Análise ética.

\section{Abstract}

In last decades urban heritage areas in Latin America have been the scenario of public and private interventions in order to conserve their heritage and increase tourist attraction. These actions have generated processes of gentrification and dispossession, whose ethical analysis is approached in this paper through the construction of a reference ethical framework applied to a specific case: Cuenca, in Ecuador.

NCJ es arquitecta, máster, magíster de Ordenación Territorial, candidata a doctora en Arquitectura y Estudios Urbanos, e-mail:

necabrera@uazuay.edu.ec 
It begins with the theoretical review of gentrification and debates about its study in Latin America, specifically in heritage areas, where the role of tourism is highlighted. We then proceed with the description of Cuenca case and close with its ethical analysis.

Keywords: Gentrification. Heritage areas. Latin America. Ethical analysis.

\section{Gentrificación en América Latina}

Desde que Ruth Glass utilizó el término "gentrificación" en 1964 -para referirse a los procesos que en la década anterior se habían generado en ciertos barrios obreros al interior de Londres donde las viviendas habían sido rehabilitadas y adquiridas por nuevos habitantes de mayores ingresos (Lees et al., 2008)-, mucho se ha estudiado y discutido sobre su conceptualización. El reciente estudio de Rojo (2016) muestra que desde su aparición distintos autores han utilizado el término para referirse a variados procesos de rehabilitación a escala urbana, en los que habitantes y usuarios de menores ingresos son desplazados debido al incremento del costo de suelo. Sin embargo, han surgido serios cuestionamientos frente a su aplicación en contextos distintos al anglosajón, con condiciones económicas, sociales y políticas diversas, donde la clase media-alta -los "gentry" (Checa-Artasu, 2011)-, y la clase trabajadora no desempeñan la misma función y aparecen factores inexistentes en el caso estudiado por Glass.

La gentrificación surge así como un "concepto caótico" (Amado, 2016) pero también "dinámico" (Checa-Artasu, 2011), por lo que su sustitución por términos más preciso ha sido formulada por autores como García (2001) quien propone el término "elitización", Carman (2011) el de "ennoblecimiento", o Mathus (2017) quien sugiere para el caso latinoamericano el híbrido "latino-gentrificación". Otros autores como Duque (2010), simplemente usan el término en inglés "gentrification". No obstante, el neologismo "gentrificación" ha terminado imponiéndose dentro del círculo académico a partir de 2009 (Janoschka et al., 2013). En medio de este complejo escenario la gentrificación “[...] representa uno de los principales campos de batalla teóricos e ideológicos para el urbanismo y la geografía urbana, con posturas epistemológicas y políticas contrastadas" (López, 2009, p. 155).

De entre las posturas que buscan explicar el fenómeno de la gentrificación Leyva (2015) y Manrique (2013) identifican dos principales, surgidas a finales de los setenta: la marxista propuesta por Neil Smith y la cultural planteada por David Ley. La teoría marxista se basa en el análisis económico, centrado en la oferta inmobiliaria donde los promotores, el sector bancario y los planificadores son actores principales. Bajo esta lógica los espacios urbanos degradados se regeneran en busca de la mayor ganancia económica. La teoría cultural se basa en el análisis de la demanda sociocultural de las ciudades posmodernas, donde aparece una nueva clase social con mejores salarios que demanda nuevos espacios. Hoy ambas teorías no son abordadas "[...] ya como causas aisladas sino como factores complementarios" (Leyva, 2015, p. 86).

Otros trabajos se han centrado en el estudio de los efectos de la gentrificación, evidenciándose dos posturas básicas: la positiva encabezada por Sabatini et al. (2009) y la crítica planteada por Bridge et al. (2011). La postura positiva señala que el mejoramiento generado reduce la segregación, fomenta la mezcla social, disminuye la necesidad de infraestructura en la periferia, mejora la estética del sector intervenido, incrementa las recaudaciones del gobierno local, en general produce beneficios para todos los involucrados. La postura crítica señala impactos negativos como desplazamientos involuntarios de clases vulnerables, ganancias únicamente para el sector inmobiliario, conflictos sociales, aumento de viviendas desocupadas, incremento del costo del suelo y de los servicios, y se respalda en múltiples estudios que no han demostrado mezcla social.

En medio de estos debates, el caso latinoamericano supone un evidente quiebre a la lógica anglosajona ligada al uso del término (Rojo, 2016). Janoschka (2016) propone en su estudio sobre gentrificación, desplazamiento y desposesión en ciudades latinoamericanas una aproximación al fenómeno desde una visión más amplia e incorpora a las dimensiones económico-financiera y política, la simbólica y psicológica. Por otra parte, Checa-Artasu (2011) menciona tres particularidades de esta región: las 
políticas públicas, el régimen de propiedad y el grado de planeamiento urbano; mientras Díaz (2015, p. 26) señala cuatro aspectos específicos de una primera oleada de gentrificación en América Latina:

[...] la primacía de las políticas públicas como detonantes de los procesos, la relevancia de los enclaves históricos y la cuestión del patrimonio en relación con su aprovechamiento turístico comercial, el poder de las clases populares para dificultar los procesos y la vulnerabilidad de las clases medias como consumidores... dando lugar a una sustitución de los usuarios muy dilatada en el tiempo y a un aburguesamiento todavía tenue.

Estos fenómenos no derivan únicamente en un cambio de composición socio-económica sino en la purga de manifestaciones culturales populares (Leyva, 2015) y de su estética, asociadas a la pobreza, la ignorancia e íntimamente relacionadas con lo indígena. Salinas (2013) se refiere a tres mecanismos para su ejecución: expulsión de la informalidad del espacio público en la construcción de una "imagen urbana depurada", intervenciones en el patrimonio arquitectónico como atractivos para el turismo y la inversión extranjera, y promoción de la inversión privada con su consecuente elitización.

En los estudios revisados el patrimonio desempeña un papel fundamental, que según Díaz (2015) se evidencia en las grandes urbes de la región, donde se concentran los valores culturales e históricos óptimos para el desarrollo inmobiliario-financiero y turístico y se han puesto en marcha desde los ochenta estrategias importadas como "[...] desregulación del mercado de suelo, megaeventos y megaproyectos, mercantilización del patrimonio, promoción del tejido comercial enfocado al turismo, etc." (Díaz, 2015, p. 17). Leyva (2015) afirma que este accionar se justifica en la protección del patrimonio y su puesta en valor, respaldada en el Tratado de las Naciones Unidas sobre la Defensa y Conservación del Patrimonio Histórico.

\section{Papel del turismo en áreas patrimoniales}

Las particularidades de la gentrificación en áreas patrimoniales radican en el creciente interés por la conservación del patrimonio y el turismo cultural. Por una parte, la conservación del patrimonio requiere la inversión de grandes sumas de dinero, y en un intento de conservar y revalorizar su patrimonio, los gobiernos locales y nacionales asumen estas inversiones y ven en el turismo una opción de financiación (García et al., 2007). Por otra, la industria advierte en la carga cultural, histórica y simbólica del patrimonio una oportunidad (Carrión, 2013), un “[...] componente detonador del prestigio turístico de un destino, al mismo tiempo que la materia prima que sustenta el consumo cultural de los visitantes" (Navarrete, 2017, p. 66). Pero el desarrollo turístico demanda políticas públicas que reduzcan obligaciones fiscales y promuevan el gasto público en infraestructura turística, que comprende desde subvenciones y apoyos económicos para la rehabilitación de edificaciones privadas hasta la regeneración del espacio público (Borja, 2013). Estas intervenciones conllevan el desplazamiento progresivo de los habitantes originales y la prohibición de ciertos usos antes permitidos en el espacio público, todo con el fin de lograr espacios atractivos para el turismo (Janoschka et al., 2013).

Diversos autores (Janoschka et al., 2013; Díaz, 2015; Leyva, 2015; Rojo, 2016) señalan que en América Latina los procesos de gentrificación en ciudades históricas son muy frecuentes y los relacionan directamente con la industria del turismo, que opera como promotora de la regeneración de zonas urbanas de valor patrimonial con potencial turístico. Este fenómeno demanda "[...] el cambio de uso de suelo habitacional o mixto con actividades comerciales tradicionales a un uso comercial y de servicios con vocación internacional" (Navarrete, 2017, p. 65). La industria del turismo promueve esta actividad bajo la promesa de un desarrollo sustentable que logre la recuperación funcional del patrimonio y la dinamización de las economías locales (González, 2007). Sin embargo, las principales estrategias para promover el turismo en áreas urbanas patrimoniales han apelado a la competitividad y el marketing que buscan incrementar la satisfacción del turista (Molina et al., 2014) y no la del habitante, desencadenando una lucha permanente por el espacio (Campuzano et al., 2014). Los habitantes de menores ingresos que habitan las áreas históricas patrimoniales no son reemplazados por habitantes de la misma ciudad de 
mayor poder adquisitivo sino por turistas o residentes de estancia corta. Navarrete (2017) señala a este fenómeno como un proceso de "turistificación".

Delgadillo (2008) afirma que, salvo contadas excepciones, los programas de rehabilitación del patrimonio edificado no han considerado a la población de bajos ingresos que habita los centros históricos latinoamericanos y que las declaratorias de patrimonio de la UNESCO han jugado un papel fundamental en sus procesos de gentrificación. El objetivo de los programas de rehabilitación ha consistido en volver más atractiva a la ciudad para el turista incidiendo en su morfología y tejido social, y promoviendo procesos de segregación socio-espacial (Borja, 2013). Como señala Lefebvre (1969, p. 125)

[...] la ciudad históricamente formada se deja de vivir, y deja de aprehender prácticamente, y queda solo como objeto de consumo cultural para turistas y para el esteticismo, ávidos de espectáculos de lo pintoresco.

Si bien la relación entre patrimonio, turismo y gentrificación se enmarca en un proceso de orden global, en América Latina presenta particularidades concretas cuyo estudio se encuentra en creciente desarrollo destacando investigaciones realizadas por Hiernaux \& González (2014) en Querétaro y Ciudad de México; Gómez et al. (2011) y García \& Sequera (2013) en Buenos Aires; Frúgoli \& Sklair (2014) y Goulart Duarte (2005) en São Paulo y Río de Janeiro; Díaz (2015) y Leyva (2015) en Bogotá; Posso (2015) en Cartagena de Indias; Castillo (Díaz, 2015) en Lima; y Sabatini et al. (2009) y Mathus (2017) en Santiago de Chile. Aunque este fenómeno regional alberga características similares, cada caso presenta diferencias (Carrión, 2000).

La revisión de estos estudios evidencia aspectos transversales como el papel cardinal de las políticas públicas, que bajo argumentos como “[...] propiciar ingresos fiscales en la zona, generar empleos, mejorar la calidad de vida de sus habitantes, recuperar las funciones urbanas y lograr competitividad" (Leyva, 2015, p. 91) han implementado estrategias de renovación en áreas patrimoniales. Las políticas públicas han ejercido una influencia directa y fundamental en casos como el de Ciudad de México donde se implementó una serie de políticas desregulatorias, que permitieron suprimir la protección sobre los alquileres y facilitaron la mercantilización del suelo y la entrada de capitales inmobiliarios; o el de Buenos Aires donde las políticas se fundamentaron en un tipo de "empresarialismo urbano" que propició la alianza público-privada de la que terminaría ganando el sector inmobiliario (Díaz, 2015).

No obstante, las políticas con mayor incidencia han sido las que protegen el patrimonio bajo un discurso conservacionista apegado a los lineamientos de entidades supranacionales como la UNESCO y que han derivado en normativas de protección del patrimonio. En Bogotá hicieron menos atractiva la inversión en las zonas patrimoniales, acelerando su deterioro e incrementado el "rent gap", potenciando su carácter gentrificable y propiciando una posterior entrada masiva de capitales. En Lima el fracaso de las políticas conservacionistas abrió paso a la agresiva intervención del mercado inmobiliario. Em Cartagena de Indias incidieron en la identidad y el imaginario ciudadano, generando una amplia aceptación (Díaz, 2015) e invisibilizando los desplazamientos.

La limpieza social y la criminalización de la economía informal -también promovidas por políticas públicas-, constituyen otro de los aspectos claves del fenómeno en la región, como lo demuestra de manera dramática la persecución policial, confiscación y represión que desde 1998 se promovió en Bogotá, bajo argumentos como la regeneración del espacio público y la eliminación de la delincuencia. Los conflictos sociales desencadenados por este tipo de políticas han traído a discusión "[...] conceptos fundamentales [como]: el derecho al trabajo frente a la necesidad del espacio público" (Leyva, 2015, p. 96).

La lógica del "urbanismo escenográfico" aparece como otro factor que marca este fenómeno y se sustenta en la espectacularización del patrimonio con el fin de atraer inversiones y fomentar la industria del turismo. Manrique (2013) señala al patrimonio como un valor agregado en la creación de una marca ciudad, donde el centro histórico se transforma en un "[...] producto que aprovecha la concentración de capital simbólico acumulado" (Díaz, 2015, p. 20), y logra visibilizar ciudades poco conocidas.

Este análisis intenta configurar un marco general sobre la gentrificación en áreas patrimoniales latinoamericanas, con base en estudios ya realizados, que han puesto de manifiesto la predominancia de una gentrificación planificada entre autoridades públicas y grandes capitalistas, que tal como en el caso 
mexicano se ha fundamentado en la renovación del espacio público y privado de los centros históricos y la atracción de nuevos grupos sociales (Díaz, 2015). Por otra parte, es importante indicar que a la fecha las investigaciones se concentran en las ciudades de mayor jerarquía: capitales nacionales o distritales.

\section{Cuenca como caso de estudio}

Con el fin de aportar a las reflexiones planteadas se propone una aproximación al caso ecuatoriano. Ecuador cuenta con dos centros históricos declarados Patrimonio Cultural de la Humanidad por la UNESCO: Quito y Cuenca. Ambos han sido objeto de políticas de conservación del patrimonio y promoción del turismo cultural, con el consecuente desplazamiento de usos y usuarios. San Francisco de Quito, capital de Ecuador, fundada en 1534 por los españoles, obtuvo la declaratoria en 1978, debido al excepcional valor de su centro histórico, considerado "[...] el mejor conservado y menos alterado de toda América Latina" (UNESCO, 2017a), cubriendo un total de 375 ha. El Centro Histórico de Santa Ana de los Ríos de Cuenca, fundada en 1557 por los españoles sobre la ciudad indígena de Tomebamba, obtuvo la declaratoria en 1999, debido a su carácter colonial que muestra "[...] la estricta normativa urbanística promulgada... por el emperador Carlos V" (UNESCO, 2017b), pues su trazado original así como otras disposiciones establecidas en Las Leyes de Indias se conservan hasta nuestros días. Actualmente su delimitación bordea las 224 ha (Figura 1).

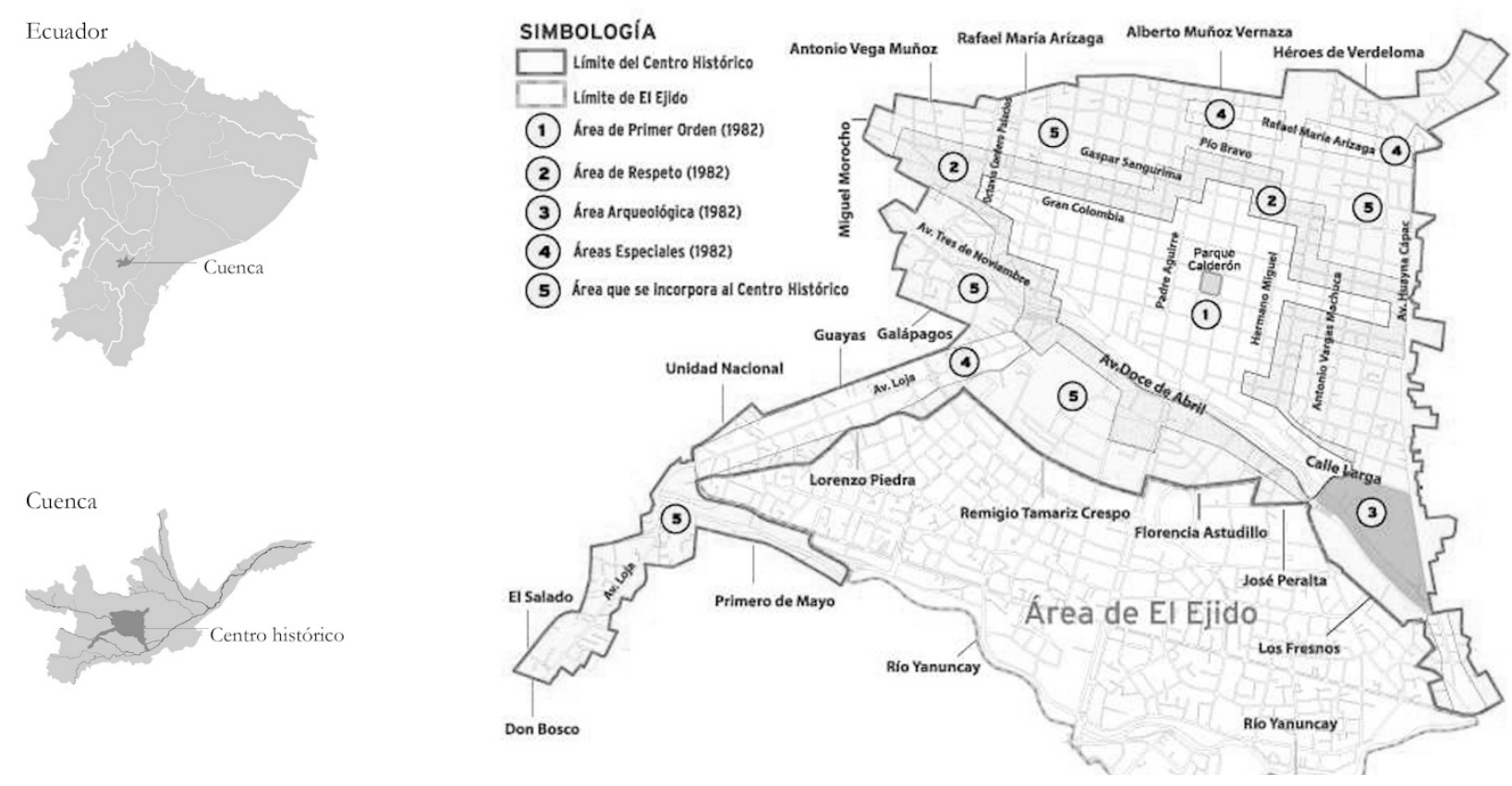

Figura 1 - Centro Histórico de Cuenca. Fuente: GAD Municipal de Cuenca (2016).

Se elige a Cuenca como caso de estudio debido al éxito que ha mostrado como destino turístico a raíz de la declaratoria de su casco histórico como Patrimonio Cultural de la Humanidad (UNESCO, 2015), basado en políticas de conservación del patrimonio edificado, regeneración del espacio público y restricción de sus usos, que ha generado procesos de gentrificación; y debido a su condición de ciudad de menor jerarquía. Cuenca es la urbe intermedia más poblada dentro de la red de ciudades del país, que según proyecciones en 2020 bordeará los 450.000 habitantes y que a partir de la segunda mitad del siglo XX ha atravesado una significativa etapa de expansión urbana (Hermida et al., 2015).

En 1982 con el Plan de Desarrollo Urbano del Área Patrimonio de Cuenca (PDUAMC) se delimitó el centro histórico -correspondiente a la traza en damero de la fundación española, con múltiples iglesias y conventos coloniales y una arquitectura civil del siglo XIX-, como unidad de valor patrimonial. Antes de este plan no se manejaba una noción de patrimonio y el PDUAMC planteó por primera vez su 
preservación e institucionalizó el discurso sobre el valor del patrimonio edificado. Se implementaron estrategias para descongestionar y homogeneizar el centro histórico y restringir usos, ocupación y altura edificatoria mediante una normativa. En 2003, cuatro años después de la declaratoria de la UNESCO se llevó a cabo una reforma al PDUAMC, que buscaba promocionar el área patrimonial como destino turístico y se creó la Fundación Municipal de Turismo para Cuenca. (Barrera, et al., 2008). Esta fundación arrancó una intensa campaña publicitaria que ubicó a Cuenca entre 2010 y 2016 en los dos primeros lugares del ranking mundial de las mejores ciudades para jubilados extranjeros (García et al., 2017) y en 2011 entre las 50 mejores ciudades históricas del mundo según la National Geographic (Zibell, 2012); y en 2017 y 2018 logró obtener para la ciudad el Oscar del Turismo al mejor destino en Sudamérica para estancias cortas (World Travel Awards, 2018).

De manera paralela a las estrategias de marketing urbano, el gobierno local llevó a cabo una serie de estrategias enfocadas en resaltar los atractivos de su área patrimonial y construir una imagen urbana ideal para el turismo cultural. En las últimas décadas se ejecutaron múltiples proyectos de regeneración del espacio público en el casco histórico, se promovió la rehabilitación y la restauración de edificios patrimoniales, se creó la Guardia Ciudadana (policía municipal) expresamente para el control sobre el uso del espacio público y se restringió el comercio informal, las prácticas populares y el arte callejero.

La rehabilitación del Mercado 9 de Octubre de 2009 constituye un ejemplo emblemático de las estrategias de regeneración del espacio público, ejecutadas en más del $90 \%$ de todas las plazas y parques del área patrimonial (Fundación Municipal El Barranco, 2014). Este proyecto restauró la edificación patrimonial resaltando sus atributos arquitectónicos en un riguroso ejercicio de diseño y construyó una amplia plaza donde existía venta al aire libre -típica de ciudades andinas ecuatorianas- alegando razones paisajísticas y de seguridad (Cuenca, 2009) (Figura 2). Esta intervención eliminó el comercio al aire libre y el programa arquitectónico del mercado no contempló ciertos usos populares, relacionados con prácticas indígenas como la "limpia". Los usos comerciales populares fueron desplazados porque "afeaban" el patrimonio y se restringieron actividades espontáneas y manifestaciones artísticas, reforzando políticas de control y de carácter restrictivo sobre el uso del espacio urbano (Cabrera \& Greene, 2018).

El Mercado 9 de Octubre se presenta hoy como una intervención modelo que cuenta con reconocimiento y galardones internacionales como el Premio Latinoamericano de Arquitectura Rogelio Salmona 2016 al mejor diseño de espacios públicos en América Latina, que ha aportado en el mejoramiento del paisaje urbano, la higiene del mercado y la imagen turística de la ciudad (Fundación Rogelio Salmona, 2016). No obstante, el proyecto ha sido escenario de múltiples pugnas entre los vigilantes municipales y antiguos usuarios, quienes demandan el uso de la plaza pese a las prohibiciones municipales (Toral, 2016; Montalván, 2018).

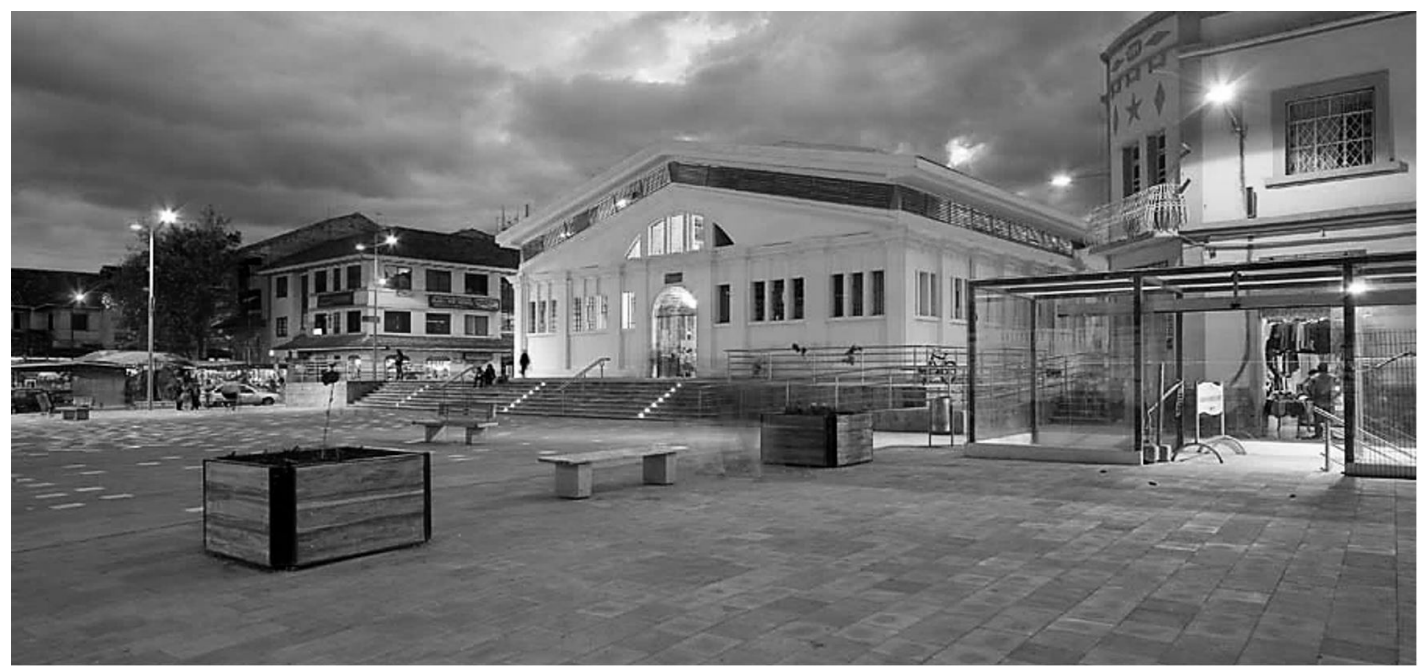

Figura 2 - Mercado 9 de Octubre. En primer plano se observa la plaza, el edificio restaurado aparece sobre los graderíos. Fuente: Albornoz (2012). 
A la intervención en espacios públicos se sumaron múltiples proyectos de rehabilitación y restauración de edificios patrimoniales, específicamente de las antiguas casonas de las élites cuencanas que se habían convertido desde los años 60 en conventillos -viviendas colectivas para familias de menores ingresos-. Estas edificaciones fueron abandonadas por las familias pudientes durante el inicio de la expansión urbana de Cuenca y se ocuparon por grupos familiares de menores ingresos, que las alquilaban por habitaciones. En este período las casonas no fueron mantenidas y se deterioraron poco a poco, pese a lo cual constituyeron el principal modo de habitar el centro histórico cuencano y una alternativa factible para resolver la demanda de vivienda hasta finales del siglo XX (Pacheco \& Sarmiento, 2015). Dentro de las estrategias de turistificación los conventillos fueron restaurados y se transformaron en hoteles, comercios y lujosos departamentos a disposición de turistas, principalmente jubilados extranjeros, quienes contaban con el poder adquisitivo suficiente para alquilar o incluso adquirir estas viviendas (Figuras 3 y 4 ).

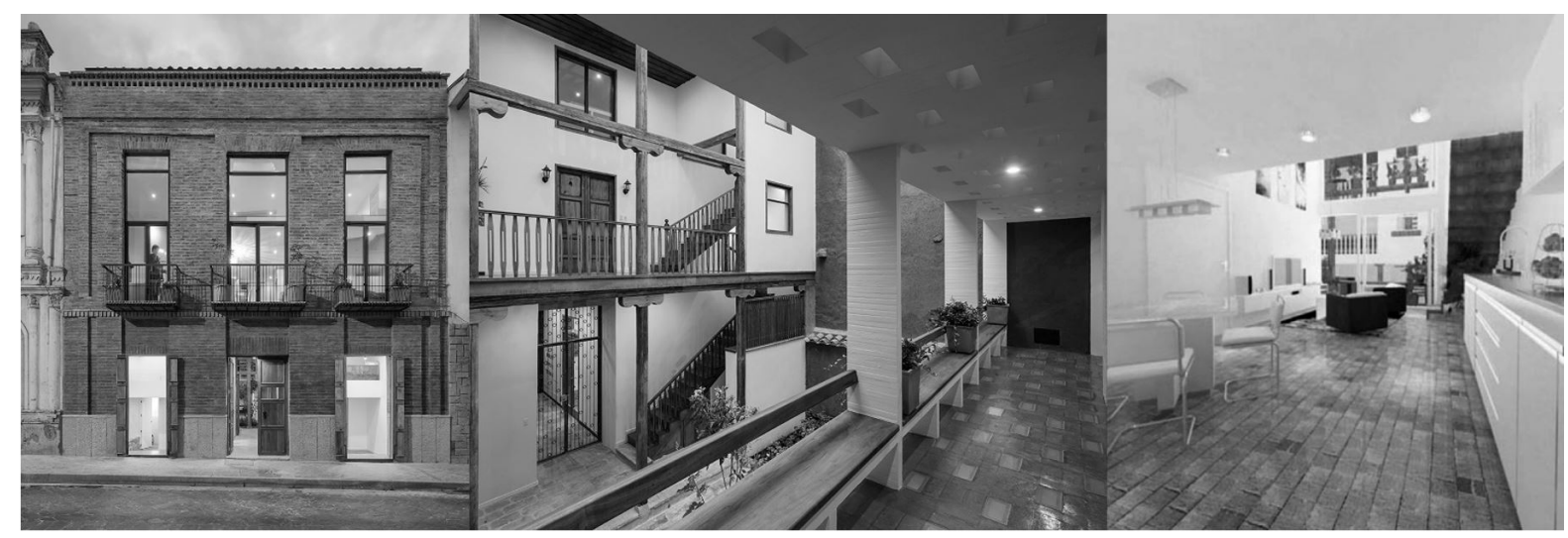

Figura 3 - Casa Juan Jaramillo, Centro Histórico de Cuenca. Fuente: Cuenca Properties (2017).

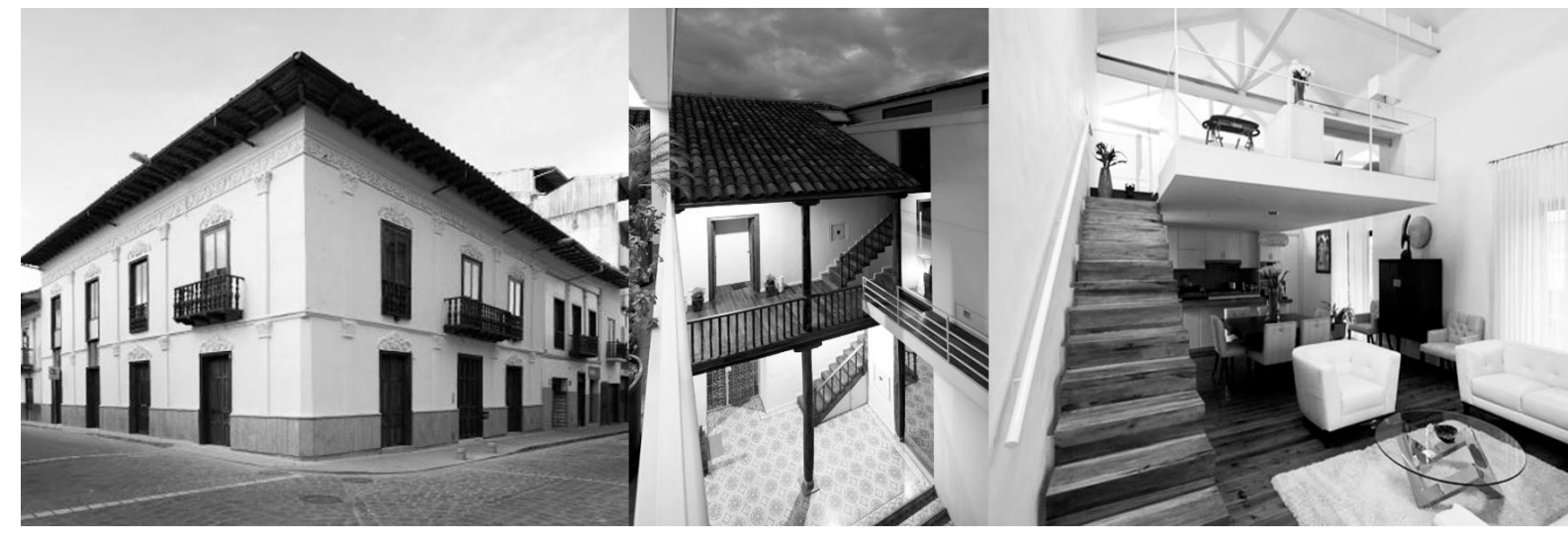

Figura 4 - Vivienda San Sebastián, Centro Histórico de Cuenca. Fuente: Cuenca Properties (2017).

Como resultado de este fenómeno, de las 67 viviendas colectivas registradas en 2000 en dos parroquias del centro histórico: El Sagrario y Gil Ramírez Dávalos, 42 habían modificado su uso en 2015 a actividades relacionadas al turismo, principalmente departamentos para estancia corta, hoteles y comercios de alto estándar (Pacheco \& Sarmiento, 2015) (Figura 5). En un primer momento la restauración de estas edificaciones contó con capitales locales, que se invirtieron tímidamente, pero en el último lustro jubilados norteamericanos han adquirido estas viviendas para restaurarlas y dividirlas en departamentos, creando incluso firmas inmobiliarias como la CuencaCentral.com para su comercialización (VIVE, 2015). 


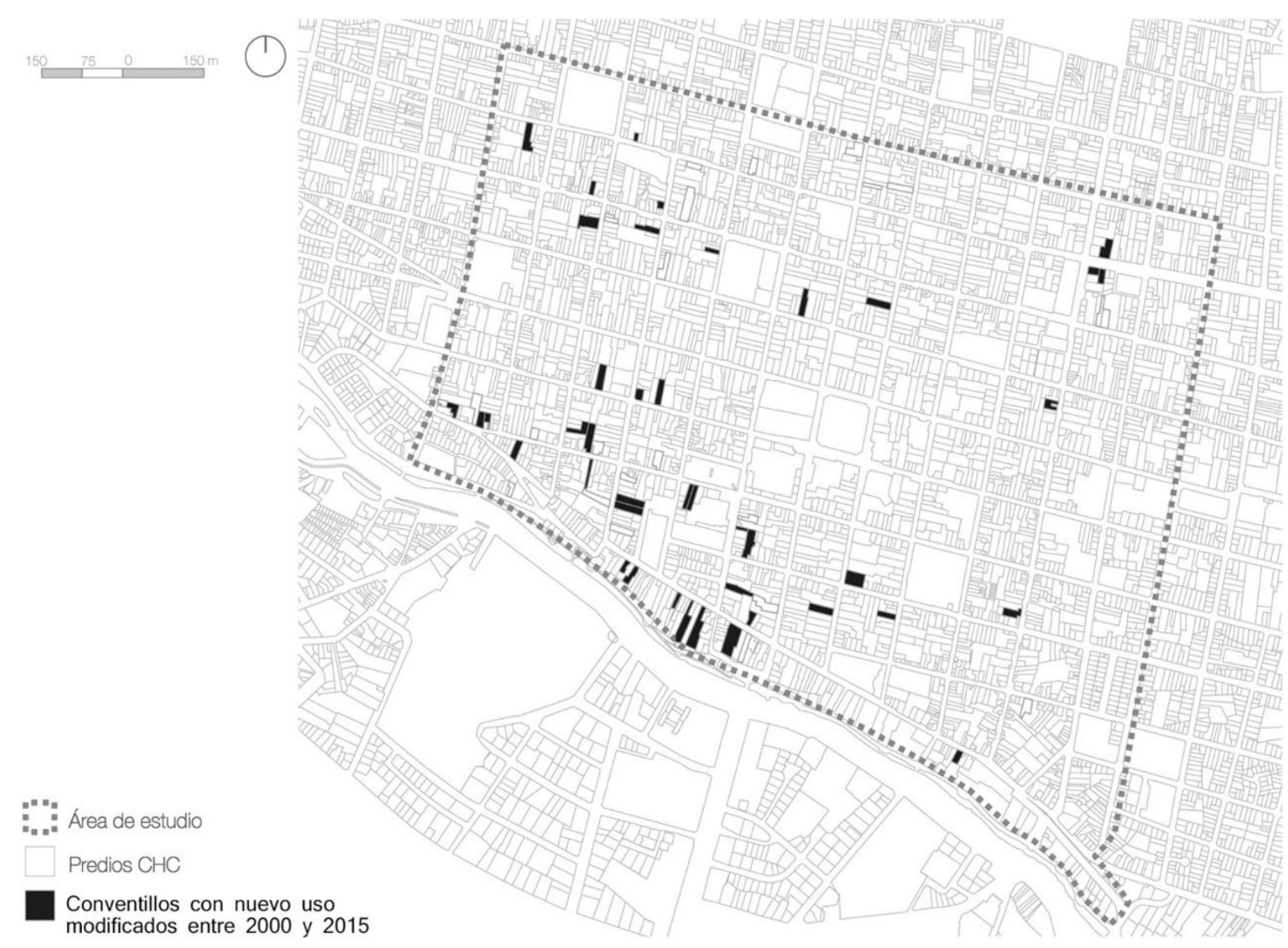

Figura 5 - Cambio de uso de los conventillos entre 2000 y 2015. Fuente: Cabrera et al. (2016, p. 729).

El régimen de alquiler permitió la rápida remoción de los inquilinos de los conventillos y su desplazamiento no ha trascendido en la opinión pública pues por muchos años se difundió la idea de que en el centro histórico no vivía nadie, situación que se puede refutar fácilmente al revisar el último Censo de Población y Vivienda de 2010, donde se constata que varias manzanas del área patrimonial se encontraban en el rango de densidades de vivienda más altas de Cuenca (INEC, 2012).

Por otra parte, las políticas para la regulación del uso de los espacios públicos en el centro histórico se reforzaron a partir de la creación de la Guardia Ciudadana de Cuenca en 2001, cuyo fin principal consistió en eliminar las prácticas populares y el comercio informal, y en apoyar las actividades turísticas (Cuenca, 2001). Esta es la estrategia que ha generado más polémica de las desplegadas hasta el momento por el gobierno local de Cuenca, dado los continuos enfrentamientos entre comerciantes informales y guardias ciudadanos (Arévalo, 2017).

Hoy el centro histórico de Cuenca es resultado de un modelo de desarrollo urbano basado en el fomento del turismo cultural, lo que ha generado procesos de gentrificación. El gobierno local presenta los títulos y premios otorgados como una muestra de su correcta gestión y los cuencanos los reciben con orgullo, pues lo asumen como el reconocimiento a los valores culturales de su ciudad. No existe un cuestionamiento serio sobre lo que ocurre con las familias desalojadas y tampoco un registro de los lugares a los que se han desplazado. Los planes de desarrollo quinquenales no revelan las ganancias reales que la ciudad ha recibido del turismo ni los datos sobre generación de empleo y pequeños emprendimientos asociados a dicha industria (Cuenca, 2010,2016), pese a los continuos reclamos de los representantes hoteleros quienes exigen mayores regulaciones y garantías frente a la demanda cambiante de la industria turística y al incremento masivo de la oferta en el área histórica de Cuenca, a la que se suma la reciente aparición de plataformas como Airbnb (JPM, 2017). De lo que sí se da cuenta en los planes es del creciente número de jubilados extranjeros acogidos, que entre 2009 y 2012 se incrementó en proporción de 1 a 15 (García et al., 2017). 


\section{Análisis ético del caso cuencano}

La Ética o "filosofía moral" se centra en el estudio de la moral, es decir de las acciones del ser humano, su fin es orientar la toma de decisiones y el gobierno de sí mismo en libertad, y cuenta con una larga trayectoria histórica. Desde las éticas tradicionales se diferencian dos corrientes: las éticas de la felicidad o teleológicas y las éticas del deber o deontológicas. Las teorías éticas contemporáneas son herederas de estas corrientes y se fundamentan en los principios de autodeterminación y autonomía, y en el derecho a decidir (Cortina, 1996), pero la ética no se refiere únicamente al accionar como individuo dentro de un colectivo, sino a los códigos éticos que todas las sociedades albergan, imprescindibles en la construcción de políticas públicas. Correa (2017) resalta la importancia de reflexionar sobre los principios éticos de las sociedades contemporáneas y la necesidad de definir un Marco Ético de Referencia (MER) en torno al cual deliberar.

Para abordar el análisis propuesto en este artículo es indispensable construir un MER en función de las teorías éticas que se cruzan en el ámbito de estudio: la gentrificación en áreas patrimoniales latinoamericanas. Se consideran los aportes de las éticas empresarial, del desarrollo, de la ciudad y la cívica. La ética empresarial plantea una reflexión sobre el fin en sí mismo de la empresa, que según Correa (2017) consiste en satisfacer las necesidades sociales a través del beneficio económico evitando la excesiva mercantilización sin responsabilidad solidaria, siendo necesario incorporar en el carácter de las "[...] organizaciones aquellos hábitos que pueden llevar a decisiones justas... a favor de la integridad y de la transparencia" (Cortina, 2004, p. 20). Sen (1993) sostiene que la ética empresarial debe dejar de tener una oscura presencia y ser reconocida claramente. Por su parte, la ética del desarrollo planteada inicialmente por Goulet (1989), ubica a la persona y su dignidad como el centro del desarrollo, en una visión marcadamente humanista y critica el modelo que persigue únicamente el crecimiento económico. En la actualidad las reflexiones de la ética del desarrollo se centran en la justicia distributiva (Correa, 2017).

En los debates sobre la ética de la ciudad se diferencian tres propuestas: 1 . El derecho a la ciudad, defendido por Lefebvre (1969), Borja (2013) y Harvey (2013), cuyo MER se basa en los derechos humanos colectivos; 2. La ciudad justa, de Fainstein (2014), cuyo MER se fundamente en la teoría de la justicia de Rawls y de diversidad de Habermas; y, 3. La ciudad ética, de Barrett et al. (2016), cuyo MER se basa en el buen gobierno, la justicia social y la mitigación del cambio climático. Por otra parte, la ética cívica resalta el papel del ciudadano como sujeto de derechos -que exige a las instituciones que los respeten-, y como participante activo de la sociedad. Todo ello dentro de la moral cívica y la moral crítica (Cortina, 1996).

Tras la revisión de estas teorías éticas contemporáneas, se propone el análisis de la gentrificación en áreas patrimoniales de América Latina, a la luz de un MER basado en las éticas del deber o deontológicas, que coloque a la comunidad y al ser humano como el eje central, defienda los principios de buen gobierno y justicia social, considere al ciudadano como sujeto de derechos e interlocutor válido y promueva su participación activa. Bajo este MER se plantea el análisis ético del caso cuencano por actores o sujetos éticos ya que cumplen diversas funciones y persigue fines distintos: gobierno local, instituciones para la salvaguarda del patrimonio, departamentos técnicos, industria del turismo y promotores inmobiliarios.

Los gobiernos locales y nacionales constituyen "[...] un actor clave por sus importantes competencias urbanísticas" (Borja, 2013, p. 298), y la posibilidad de generar políticas públicas que fomenten la justicia social (Marcuse, 2015). Pero dentro de estos organismos existen intereses políticos a los que se suman las presiones de las entidades para la protección del patrimonio y de los poderes económicos. No obstante, estas instituciones de carácter público no deben guiarse por las dinámicas del libre mercado y menos aún promover planes y programas que diferencien "[...] ciudadanos con derechos reales y otros con derechos disminuidos" (Borja, 2013, p 25).

El GAD Municipal de Cuenca, ha identificado el potencial turístico de su área patrimonial y la consecuencia lógica ha sido intervenirla, rehabilitarla e insertarla en la dinámica del turismo. Es claro que existe un interés político detrás de este accionar ya que en la última década Cuenca se ha posicionado a nivel nacional e internacional, gracias a una intensa campaña de marketing urbano, dirigida por la Fundación Municipal de Turismo para Cuenca, lo que ha permitido obtener una serie de reconocimientos 
internacionales y nacionales, galardones que siguen alimentando el marketing y respaldan el accionar del gobierno local. Sin embargo, esta hoja de ruta no se ha traducido en beneficios para toda la ciudad sino para el grupo que tiene el poder económico y ve incrementado su capital y rentabilidad, mientras los habitantes de menor poder adquisitivo que habitaban el centro histórico han sido desplazados sin contar con programas efectivos de relocalización. Actualmente no existe un registro de las familias y los comerciantes desplazados, pese a que estos últimos han protagonizado actos de resistencia combatidos mediante ejercicios de poder y de control policial.

Al abordar el papel del gobierno local en los procesos de gentrificación del área patrimonial cuencana, el conflicto ético se vuelve evidente. En Cuenca, los tomadores de decisiones argumentan que la rehabilitación del patrimonio demanda costos que las familias de menores ingresos que lo habitan en régimen de alquiler no pueden cubrir y que entonces deben relocalizarse, la gentrificación del centro histórico se presenta como un resultado menor e inevitable frente a un beneficio mucho mayor.

Las entidades internacionales encargadas de promover la conservación y la puesta en valor del patrimonio edificado, como la UNESCO y el ICOMOS, actúan con el objetivo de proteger un "patrimonio común". Estos organismos ejercen un cierto nivel de presión sobre los gobiernos nacionales y locales al demandar la conservación del patrimonio edificado bajo estándares internacionales que minimizan a la comunidad que habita dichos espacios, que con frecuencia presenta bajo poder adquisitivo (Delgadillo, 2008). Por su parte, estas entidades han convertido al patrimonio material en el fin en sí mismo, relegando al ciudadano como sujeto de derechos e interlocutor válido. Se manifiesta así una desviación en este sentido, el propósito aquí se desvirtúa, la noción de solidaridad y corresponsabilidad detrás de un patrimonio común se dispersa.

En el caso cuencano, las intervenciones de restauración, rehabilitación y regeneración del patrimonio edificado que se han efectuado a raíz de su declaratoria, gracias a créditos internacionales obtenidos con el aval de la UNESCO, han beneficiado a un grupo privilegiado originando el desplazamiento de los más vulnerables. Los resultados han sido aplaudidos por las instituciones internacionales para la salvaguarda del patrimonio sin considerar el conflicto ético originado.

Los departamentos técnicos encargados de los proyectos de intervención en Cuenca, están integrados mayoritariamente por arquitectos, quienes han enfatizado sobre aspectos estéticos y paisajísticos que buscan construir una imagen urbana ideal, cercana a la de ciudad histórica europea. Esta concepción excluye la estética de lo popular y genera proyectos de arquitectura bien resueltos dentro de una línea europeizante. El ciudadano común no es considerado interlocutor válido y su participación es evadida. De acuerdo a Fainstein (2014) los procesos de planificación e intervención urbana deben promover la justicia y favorecer a los grupos de menores ingresos y minoritarios. No obstante, las intervenciones de regeneración y rehabilitación llevadas a cabo en el área patrimonial cuencana han afectado precisamente a los grupos de menores ingresos. Los planificadores y arquitectos han favorecido en cierta medida a estos procesos, olvidando que

Un objetivo fundacional del urbanismo es contribuir a la reducción de las desigualdades entre los ciudadanos, proclamar la igualdad formal de todos los habitantes e impulsar políticas públicas que conviertan los derechos teóricos en reales (Borja, 2013, p. 270).

La industria del turismo responde a la lógica de libre mercado, basada en conceptos como competitividad y marketing, donde las necesidades sociales se omiten en la búsqueda del beneficio económico. Yeras (2008, p. 50) señala que “[...] aunque el turismo es una industria de éxito, múltiples son los factores sociales que deben valorarse, pues no está exento de riesgos". El conflicto ético central en este punto tiene que ver con la excesiva mercantilización del patrimonio edificado, el espacio público y la ciudad por parte del turismo, sin ninguna responsabilidad solidaria. Lefebvre (1972, p. 75) ya criticaba el entendimiento del suelo y la ciudad como mercancía, en que el "espacio" indispensable para la vida cotidiana se vende y se compra.

En Cuenca el turismo internacional se ha presentado como la industria sin chimeneas y una alternativa sustentable que promueve el empleo local. Sin embargo, de la manera en que hoy es asumida dista mucho de serlo pues depende de una demanda externa sumamente cambiante -jubilados norteamericanos y 
europeos-, que deja al centro histórico cuencano en una situación de suma fragilidad. Por otra parte, el empleo que ha promovido es de dos tipos, un porcentaje pequeño ligado a los estándares del turismo internacional que con frecuencia es ocupado por extranjeros y un porcentaje mayoritario que requiere personal poco calificado y de baja remuneración destinado a trabajadores locales (Cabrera, 2019). Es evidente que la industria del turismo que se ha insertado en Cuenca busca el beneficio económico privado que no necesariamente es sinónimo de un beneficio para la ciudad y sus ciudadanos.

El negocio inmobiliario se instaló en el área histórica de Cuenca en 2005 y se especializó en 2010, cuando empezaron a ofertarse "[...] varias opciones para [el] nuevo mercado": los jubilados extranjeros (VIVE, 2015, p. 1). Se explotó así la posibilidad de adquirir o arrendar una vivienda en las zonas turísticas y mejor dotadas de la ciudad (García et al., 2017). Las operaciones inmobiliarias desencadenadas contribuyeron a que Cuenca se convierta en la ciudad con el costo de suelo y de vivienda más elevado del país, según el último reporte en 2017 del Instituto Nacional de Estadísticas Censos (INEC, 2017), fomentando procesos de segregación socio-espacial e inequidades sociales.

Los promotores inmobiliarios representan el colectivo que mayor presión ha ejercido sobre el gobierno y constituyen el agente gentrificador más reacio a asumir una postura ética dentro del MER propuesto, ya que su accionar no contempla ninguno de los principios éticos considerados. Se puede afirmar que a la fecha su objetivo capital es el beneficio económico incluso por encima de las necesidades sociales.

\section{Conclusiones}

A la luz de estas reflexiones la gentrificación en el área patrimonial de Cuenca representa un proceso donde los aspectos positivos señalados por varios autores como: la desconcentración de la pobreza (Sabatini et al., 2009), la generación de oportunidades laborales (Sabatini \& Cáceres, 2004) y la recuperación de la imagen barrial (Campos \& García, 2004), no existen y se siguen promoviendo políticas, programas y proyectos de rehabilitación y regeneración de áreas urbanas patrimoniales que derivan en procesos de gentrificación, desplazamiento y desposesión.

Un importante aporte de los estudios sobre gentrificación reside en que pusieron

[...] sobre la mesa inequidades de clase e injusticias creadas por un libre mercado que favorece la construcción de ambientes urbanos que estimulan la acumulación del capital a costa de las necesidades sociales de vivienda, la comunidad o la familia (Leyva, 2015, p. 86).

En el caso cuencano existe un intento por parte del gobierno local de evitar esta discusión, de invisibilizar los efectos negativos derivados de la restauración de edificios patrimoniales, la regeneración del espacio público y la restricción de usos. No existen estudios oficiales, tampoco se cuenta con registros, los estudios realizados son aislados y parciales y los datos existentes se encuentran dispersos e incompletos.

El análisis ético del caso cuencano muestra una correspondencia en múltiples aspectos con la gentrificación en las ciudades de mayor jerarquía de América Latina y evidencia cómo ninguno de los sujetos éticos rige sus acciones y decisiones dentro del MER propuesto. El gobierno local se maneja principalmente por intereses políticos, las instituciones internacionales para la salvaguarda del patrimonio buscan la protección del patrimonio edificado omitiendo el papel de la comunidad, los departamentos técnicos encargados de los proyectos de intervención responden a una estética europeizante que persigue la eliminación de lo popular, mientras la industria del turismo y los promotores inmobiliarios buscan el beneficio económico por encima de las necesidades sociales. ¿Qué hacer entonces, cómo manejar la gentrificación en áreas urbanas patrimoniales? El conflicto tiene que ver con la exacerbación del desarrollo turístico y la manera en que se ha implementado hasta ahora, donde se intenta construir la imagen de una postal perfecta que permita comercializar la ciudad patrimonial en el mercado turístico internacional, un mercado con nostalgia del pasado y un claro rechazo a la pobreza.

Como señala Correa $(2017$, p. 3) “[...] es necesaria una transformación en la actitud ética”, que en el caso de los sujetos que intervienen en los procesos de gentrificación del área patrimonial cuencana se 
traduzca en un cambio de enfoque sobre su labor y la incidencia de sus decisiones en el tejido social, particularmente en los menos favorecidos, que según Goulet (1989) son los primeros afectados de cualquier sistema. En este sentido, es fundamental replantear las políticas urbanas desde un enfoque ético, que coloque a la comunidad y al ser humano como el eje central, que defienda los principios de buen gobierno y justicia social, que considere al ciudadano como sujeto de derechos e interlocutor válido y promueva su participación activa. Es verdad que en sociedades con profundas desigualdades como las latinoamericanas este tipo de planteamientos encuentra obstáculos profundos y puede tildarse de "utopía académica" (Musset, 2015). Sin embargo, si estos desafíos no son asumidos ni visibilizados, los derechos urbanos no pasarán del discurso político y el poder económico seguirá especulando con el espacio urbano no solo en áreas de valor patrimonial, y continuará provocando el desplazamiento de la población con menor poder adquisitivo. Finalmente, cabe cuestionarse sobre el enfoque esteticista capaz de sensibilizarse ante el patrimonio histórico edificado pero incapaz de entender el significado ético de los procesos de gentrificación, desplazamiento y desposesión.

\section{Referencias}

Albornoz, B. (2012). Mercado 9 de Octubre. Quito. Recuperado el 27 de octubre de 2018, de http://www.borisalbornoz.com/proyectos/mercado-9-de-octubre/

Amado, J. (2016). Procesos de transformación urbana en áreas centrales: aportes para el abordaje de la gentrificación en América Latina. Revista San Gregorio, (spe), 114-123.

Arévalo, M. (2017). Guardia ciudadana labora bajo amenaza. El Tiempo. Recuperado el 15 de febrero de 2019, de https://www.eltiempo.com.ec/noticias/cuenca/2/guardia-ciudadana-labora-bajo-amenaza

Barrera, J., Cabrera, L., Guerrero, L., Lazo, H., \& Pérez, I. (2008). Análisis de la evolución urbana de Cuenca (Tesis). Universidad de Cuenca, Cuenca.

Barrett, B., Horne, R., \& Fien, J. (2016). The ethical city: a rationale for an urgent new agenda. Sustainability, 8(11), $1-14$.

Borja, J. (2013). Revolución urbana y derechos ciudadanos. Madrid: Alianza Editorial.

Bridge, G., Butler, T., \& Lees, L. (Eds.). (2011). Mixed communities: gentrification by stealth? Chicago: Policy Press.

Cabrera, N. (2019). Mercado inmobiliario y metamorfosis urbana en ciudades intermedias. Gringolandia en Cuenca: la tierra prometida. Bitácora Urbano Territorial, 28(1), 91-100.

Cabrera, N., \& Greene, M. (2018). Nociones de espacio urbano en la conservación del patrimonio: el caso ecuatoriano. In III Congreso de Investigación Interdisciplinar en Arquitectura, Diseño, Ciudad y Territorio (pp. 568576). Santiago de Chile: Pontificia Universidad Católica de Chile.

Cabrera, N., Pacheco, D., \& Sarmiento, A. (2016). Posibilidades del conventillo como vivienda colectiva en centros históricos de América Latina: Cuenca-Ecuador como caso de estudio. In II Congreso Internacional de Vivienda Colectiva Sostenible (pp. 724-729). São Paulo: Fundação Armando Alvares Penteado, Universidad Politécnica de Cataluña.

Campos, D., \& García, C. (2004). Identidad y sociabilidad en las nuevas comunidades enrejadas: observando la construcción de la distancia social en Huechuraba. In G. Cáceres, \& F. Sabatini (Eds.), Barrios cerrados en Santiago de Chile: entre la exclusión y la integración social (pp. 179-207). Santiago de Chile: Pontificia Universidad Católica de Chile, Lincoln Institute of Land Policy.

Campuzano, E., Tello, C., \& Everitt, J. (2014). Spatial segregation in a tourist city: the case of Puerto Vallarta, Mexico. Journal of Latin American Geography, 13(3), 87-112.

Carman, M. (2011). El proceso de ennoblecimiento y la salida negociada de los innobles en Buenos Aires. Cadernos Metrópole, 13(25), 257-278. 
Carrión, F. (2000). Centro histórico: relación social, globalización y mitos. In F. Carrión (Ed.), Desarrollo cultural y gestión en centros históricos. Quito: Flacso.

Carrión, F. (2013). Urbicidio o la producción del olvido. In L. Durán, E. Kingman, \& M. Lacarrieu (Eds.), Foro habitar el patrimonio: nuevos aportes al debate desde América Latina (pp. 116-130). Quito: Instituto Metropolitano de Quito, Flacso Ecuador.

Checa-Artasu, M. (2011). Gentrificación y cultura: algunas reflexiones. Revista Bibliográfica de Geografía y Ciencias Sociales, VXI(914), 1-37.

Correa, M. (2017). La ética de las profesiones: en la construcción de una sociedad igualitaria. Documento no publicado.

Cortina, A. (1996). El estatuto de le ética aplicada. Hermenéutica Crítica de las actividades humanas. Isegoría, 13, 119-134.

Cortina, A. (2004). Construir confianza. Madrid: Trotta.

Cuenca. Concejo Cantonal. (2001, 14 de junio). Ordenanza nº 145. Ordenanza de Creación y Funcionamiento de la Guardia Ciudadana de Cuenca. Cuenca: GAD Municipal de Cuenca.

Cuenca. GAD Municipal. (2009). Mercado, barrio y ciudad: historia de “La Nueve”. Cuenca: GAD Municipal de Cuenca.

Cuenca. GAD Municipal. (2010). Plan de ordenamiento territorial de Cuenca. Cuenca: GAD Municipal de Cuenca.

Cuenca. GAD Municipal. (2016). Actualización del Plan de Ordenamiento Territorial de Cuenca. Cuenca: GAD Municipal de Cuenca.

Cuenca Properties. (2017). Cuenca properties. Recuperado el 20 de septiembre de 2018, de http://www.cuencaproperties.com

Delgadillo, V. (2008). Mejoramiento habitacional en las áreas urbanas centrales de América Latina. Del combate de tugurios a la rehabilitación habitacional progresiva. Revista INVI, 63(23), 89-120.

Díaz, I. (2015). Perspectivas del estudio de la gentrificación en América Latina. In V. Delgadillo, I. Díaz, \& L. Salinas (Eds.), Perspectivas del estudio de la gentrificación en México y América Latina (pp. 11-31.). México: UNAM.

Duque, R. (2010). El concepto de gentrification en España: reflexión teórica y debate terminológico. Revista Bibliográfica de Geografía y Ciencias Sociales, 15(875), 1-14.

Fainstein, S. (2014). The just city. International Journal of Urban Science, 18(1), 1-18.

Frúgoli, H., Jr., \& Sklair, J. (2014). O bairro da luz em São Paulo: questões antropológicas sobre o fenômeno da gentrification. Cadernos de Antropologia Social, (30), 119-136.

Fundación Municipal El Barranco. (2014). Cuenca: proyectos de revitalización urbana, 2009-2014. Cuenca: GAD Municipal de Cuenca.

Fundación Rogelio Salmona. (2016). Obra ganadora Segundo Ciclo. Recuperado el 29 de octubre de 2018, de http://premio.fundacionrogeliosalmona.org/archivo/segundo-ciclo/89-mercado-9-de-octubre-y-plazarotary.html

García, E., \& Sequera, J. (2013). Dinámicas de gentrificación en metrópolis de la cultura: aproximación comparada a las estrategias de Madrid y Buenos Aires. In V Seminario Internacional de Investigación en Urbanismo, BarcelonaBuenos Aires (pp. 561-569). Barcelona: DUOT.

García, L. (2001). Elitización: propuesta en español para el término gentrificación. Revista Bibliográfica de Geografía y Ciencias Sociales, 3(332).

García, L., Smith, N., \& Mejías, M. (2007). Gentrification, displacement, and tourism in Santa Cruz de Tenerife. Urban Geography, 28(3), 276-298. 
García, M., Osorio, P., \& Pastor, L. (2017). Estudio sobre los impactos socio-económicos en Cuenca de la migración residencial de norteamericanos y europeos: aportes para una convivencia armónica local. Cuenca. Informe de consultoría.

Gómez, M., Almirón, A., \& González, M. (2011). La cultura como recurso turístico de las ciudades: el caso de la patrimonialización del tango en la ciudad de Buenos Aires. Estudios y Perspectivas en Turismo, 20(5), 1027-1046.

González, R. (2007). Metodología para establecer orden de prioridad de intervención en un centro histórico con vista a su desarrollo turístico. Retos Turísticos, 2(6), 9-13.

Goulart Duarte, R. (2005). 0 processo de reabilitação urbana na cidade do Rio de Janeiro e suas perspectivas. Scripta Nova: Revista Electrónica de Geografía y Ciencias Sociales, 9(194), 44.

Goulet, D. (1989). Tareas y métodos en la ética el desarrollo. Revista de Filosofia de la Universidad de Costa Rica, 27(66), 293-305.

Harvey, D. (2013). Ciudades rebeldes: del derecho a la ciudad a la revolución urbana. Madrid: Akal.

Hermida, A., Hermida, C., Cabrera, N., \& Calle, C. (2015). La densidad urbana como variable de análisis de la ciudad: el caso de Cuenca, Ecuador. Revista de Estudios Urbano Regionales, 41(124), 25-44.

Hiernaux, D., \& González, C. (2014). Gentrificación, simbólica y poder en los centros históricos: Querétaro, México. Scripta Nova: Revista Electrónica de Geografía y Ciencias Sociales, 18(493), 1-12.

Instituto Nacional de Estadísticas Censos - INEC. (2012). Censo de población y vivienda 2010. Quito: INEC.

Instituto Nacional de Estadísticas Censos - INEC. (2017). Reporte mensual, Diciembre. Quito: INEC.

Janoschka, M. (2016). Gentrificación, desplazamiento, desposesión: procesos urbanos claves en América Latina. Revista INVI, 31(88), 22-71.

Janoschka, M., Sequera, J., \& Salinas, L. (2013). Gentrification in Spain and Latin America: a critical dialogue. International Journal of Urban and Regional Research, 38(2), 155-171.

JPM. (2017). Sector hotelero anuncia pérdidas. El Tiempo. Recuperado el 17 de febrero de 2019, de https://www.eltiempo.com.ec/noticias/cuenca/2/sector-hotelero-anuncia-perdidas

Lees, L., Slater, T., \& Wyly, E. (2008). Gentrification. Londres: Routledge.

Lefebvre, H. (1969). El derecho a la ciudad. Barcelona: Península.

Lefebvre, H. (1972). Espace et politique: le droit à la ville II. París: Éditions Anthropos.

Leyva, N. (2015). El papel de las instituciones culturales en el proceso de gentrificación del barrio La Candelaria de Bogotá: un estudio de caso. Cuadernos de Música y Artes Escénicas, 1(2), 83-106.

López, E. (2009). Gentrificación. Revista de Geografía Norte Grande, 44, 155-158.

Manrique, A. (2013). Gentrificación de La Candelaria: reconfiguraciones de lugar de residencia y consumo de grupos de altos ingresos. Revista Colombiana de Geografía, 22(2), 211-234.

Marcuse, P. (2015). Gentrification, social justice and personal ethics. International Journal of Urban and Regional Research, 39(6), 1263-1269.

Mathus, C. (2017). Estilos de vida e imaginarios urbanos en nuevos residentes de Lastarria y Bellas Artes: el barrio patrimonial como escenario de diversidad, distinción y movilidad. Revista Latinoamericana de Estudios Urbano Regionales, 43(129), 165-186.

Molina, R., Ochoa, M., \& Leco, C. (2014). Políticas públicas y factores que determinan la competitividad turística de Morelia, México y de Alcalá de Henares, España. CIMEXUS, IX(2), 49-66.

Montalván, D. (Ed.). (2018). Resolver informalidad es deuda pendiente del Municipio. El Mercurio. Recuperado el 27 de octubre de 2019, de https://ww2.elmercurio.com.ec/2018/08/04/resolver-informalidad-es-deuda-pendientedel-municipio/ 
Musset, A. (2015). El mito de la ciudad justa. Bitácora Urbano Territorial, 25(1), 125-139.

Navarrete, D. (2017). Turismo gentrificador en ciudades patrimoniales. Exclusión y transformaciones urbanoarquitectónicas del patrimonio en Guanajuato, México. Revista INVI, 32(89), 61-83.

Pacheco, D., \& Sarmiento, A. (2015). El conventillo como tipología de vivienda en el Centro Histórico de Cuenca: propuesta de intervención Casa Armijos (Tesis). Facultad de Arquitectura y Urbanismo, Universidad de Cuenca, Cuenca.

Posso, L. (2015). Patrimonialización, especulación inmobiliaria y turismo: gentrificación en el barrio Getsemaní. In V. Delgadillo, I. Díaz, \& L. Salinas (Eds.), Perspectivas del estudio de la gentrificación en México y América Latina (pp. 175-190). México: UNAM.

Rojo, F. (2016). La gentrificación en los estudios urbanos: una exploración sobre la producción académica de las ciudades. Cadernos Metrópole, 18(37), 697-719.

Sabatini, F., \& Cáceres, G. (2004). Los barrios cerrados y la ruptura del patrón tradicional de segregación en las ciudades latinoamericanas: el caso de Santiago de Chile. In G. Cáceres, \& F. Sabatini (Eds.), Barrios cerrados en Santiago de Chile: entre la exclusión y la integración social (pp. 9-44). Santiago de Chile: Pontificia Universidad Católica de Chile, Lincoln Institute of Land Policy.

Sabatini, F., Sarella, M., \& Vásquez, H. (2009). Gentrificación sin expulsión, o la ciudad latinoamericana en una encrucijada histórica. Revista 180, (24), 18-25.

Salinas, L. (2013). Gentrificación en la ciudad latinoamericana, el caso de Buenos Aires y Ciudad de México. GeoGraphos, 44(4), 283-307.

Sen, A. (1993). Does business ethics make economic sense? Business Ethics Quarterly, 3(1), 45-54.

Toral, R. (Ed.). (2016). Enfrentamiento entre comerciantes y Guardia Ciudadana. El Tiempo. Recuperado el 15 de mayo de 2018, de https://www.eltiempo.com.ec/noticias/sucesos/9/enfrentamientos -entre-comerciantes-yguardia-ciudadana

United Nations Educational, Scientific and Cultural Organization - UNESCO. (2015). Centro histórico de Santa Ana de los Ríos de Cuenca. Recuperado el 7 de junio de 2018, de https://whc.unesco.org/es/list/863

United Nations Educational, Scientific and Cultural Organization - UNESCO. (2017a). Ciudad de Quito. Recuperado el 25 de abril de 2018, de https://whc.unesco.org/es/list/2

United Nations Educational, Scientific and Cultural Organization - UNESCO. (2017b). Centro histórico de Santa Ana de los Ríos de Cuenca. Recuperado el 25 de abril de 2018, de https://whc.unesco.org/es/list/863

VIVE. (2015). Extranjeros cambian el modelo inmobiliario en Cuenca. Recuperado el 20 de noviembre de 2018, de http://blog.vive1.com/extranjeros-cambian-el-modelo-inmobiliario-en-cuenca

World Travel Awards. (2018). 2017 World Travel Awards. Recuperado el 15 de febrero de 2019, de https://www. worldtravelawards.com/nominees/2018

Yeras, M. (2008). Turismo urbano, alternativa sustentable para la conservación de las ciudades. Retos Turísticos, $5(2), 48-54$.

Zibell, M. (2012). Cuenca, la “ciudad prometida" para los estadounidenses. BBC Mundo. Recuperado el 16 de enero de 2018, de http://www.bbc.com/mundo/movil/noticias/2012/12/121226_cuenca_ciudad_para_ estadounidenses_en_ecuador_mz.shtml

Editor: Paulo Nascimento Neto

Recibido: Nov. 02, 2018

Aprobado: Mayo 28, 2019 